\title{
Preliminary Study on Features of Lightning Discharge around Japan Using World Wide Lightning Location Network Data
}

\author{
Hiroyuki Iwasaki \\ Faculty of Education, Gunma University, Gunma, Japan
}

\begin{abstract}
Features of lightning around Japan over a four-year period are described using World Wide Lightning Location Network data based on global observations of very low frequency radio waves. Lightning density over land is lower than that over the ocean and the oceanic area of high density runs along the Kuroshio Current. The zone of highest density is found to the west of the Nansei Islands; however, very strong lightning rarely occurs there. Conversely, lightning density decreases gradually towards the eastern part of the Kuroshio Current, where the occurrence of very strong lightning increases.

The ratio of very strong lightning in most of the analysis area tends to increase in the cold season, and it becomes large in areas where lightning frequency is low. Furthermore, both very weak and strong lightning have a tendency to occur in areas where rain intensity is not strong.

(Citation: Iwasaki, H., 2014: Preliminary study on features of lightning discharge around Japan using World Wide Lightning Location Network data. SOLA, 10, 98-102, doi:10.2151/sola. 2014-020).
\end{abstract}

\section{Introduction}

Lightning is a familiar atmospheric phenomenon for the Japanese. However, to date, the climatological features of lightning have not been studied satisfactorily because of the limitation of available lightning data. The Japan Meteorological Agency (JMA 1968) investigated the climatological seasonal distribution of lightning over the Japanese archipelago using visual and auditory observation data. Based on JMA lightning data since the 1960s, the decadal variation in lightning frequency has been investigated (e.g., Kitagawa 1989; Yoshida 2002). Some researchers have prepared maps of the climatological frequency of lightning over the Japanese archipelago based on radio waves emitted by lightning strokes, and have examined its seasonal variation (e.g., Shindo et al. 2012). Saito et al. (2012) reported on the seasonal variation of high-current lightning discharges; however, these data were limited to land and therefore, it was impossible to describe the features of lightning over the open ocean.

Kawasaki and Yoshihashi (1998) indicated that the zone with high frequency lightning flashes, detected by the Tropical Rainfall Measuring Mission Lightning Imaging Sensor (TRMM/LIS), is elongated from the southwest to the northeast over the Pacific Ocean south of Japan, and they identified the possibility that this high-frequency zone is associated with storm tracks in the winter season. However, TRMM's orbital path prevents it from observing Japan continuously and from observing areas poleward of 35 degrees; therefore, to deepen the understanding of lightning climatology around Japan, data with greater spatiotemporal coverage are required.

A lightning data set, derived from the ground-based World Wide Lightning Location Network (WWLLN), became available in April 2004, and some researchers have revealed the features of global and/or regional lightning climatology (e.g., Virts et al. 2013). Furthermore, WWLLN data have the advantage over

Corresponding author: Hiroyuki Iwasaki, Gunma University, 4-2, Aramaki, Maebashi, 371-8510, Japan. E-mail: iwasaki@gunma-u.ac.jp. C2014, the Meteorological Society of Japan.
TRMM/LIS data of detecting information on stroke energy. In this study, the distribution features and seasonal progression of lightning are described with consideration of the strength of lightning energy.

\section{Data}

The WWLLN comprises over 60 receiving sites detecting very low frequency (VLF) radio waves $(6-18 \mathrm{kHz})$ emitted by lightning strokes, and it is particularly sensitive to cloud-toground lightning strokes. The dispersed waveform (the so-called "sferic") of the lightning impulse is processed at each receiving site and the location of the lightning is determined based on the time of group arrival of the VLF waves, detected at more than five stations (Dowden et al. 2002). The WWLLN algorithm can detect lightning with a 5-km spatial accuracy and $15-\mu$ s temporal accuracy, and its detection efficiency is $11 \%$ for all strokes and $>$ $30 \%$ for more powerful strokes (Rodger et al. 2004; Abarca et al. 2010).

In addition, using a new algorithm, radiated VLF stroke energy, related directly to the return-stroke peak currents, was re-calculated using root-mean-square energy from $7-18 \mathrm{KHz}$ with 1.33-ms sample times for all lightning strokes recorded since April 2009. The sferic attenuation along the path was calculated based on the ionospheric model with regard to the influence of its diurnal variation. In comparison with ground-based lightning data detected by IMPACT-ESP2 sensors over New Zealand, the coefficient of determination $\left(\mathrm{R}^{2}\right)$ for the estimated peak currents between the two sensors was 0.92 (Hutchins et al. 2012a).

It is known that the WWLLN is more likely to detect TRMM/ LIS lightning that occurs over the ocean than over the continent, and one of the reasons for this is the difference in conductivity between the ocean and continent (Hutchins et al. 2012b). However, according to Hutchins et al. (2012b), the relative detection efficiency of the WWLLN over the analysis region is about $0.8-0.9$. Thus, for this study, the stroke density measured by WWLLN was not corrected.

To investigate the relationship between lightning and rain intensity, JMA composite radar precipitation data are used. The JMA C-band radar network comprises 20 radar sites that collect data across 19 elevation angles every 10 minutes. Constant Altitude Plane Position Indicator data at an altitude of $2 \mathrm{~km}$ with a $1-\mathrm{km}$ mesh were produced over the blue-shaded area in Fig. 1, and the radar echo intensities were converted into precipitation intensities. As the JMA radar cannot observe some parts of the analysis area over the ocean, the hourly Global Satellite Mapping of Precipitation (GSMaP) product with a grid resolution of $0.1^{\circ}$ latitude and longitude, calculated using combined satellite microwave and infrared data, are used to estimate the distribution of rainfall (e.g., Kubota et al. 2007). The GSMaP products used in this study are composed of two data sets: the GSMaP_Microwave-IR Combined product (Ver. 5.22.1) from April 2009 to November 2010, and the GSMaP Near Real Time (GSMaP NRT) product from December 2010. Although the GSMaP_ $\bar{N} R T$ product was calculated using simple algorithms, the two types of GSMaP product were analyzed in a same manner in this study.

\section{Analysis method}

The location and time of the lightning strokes are used to 


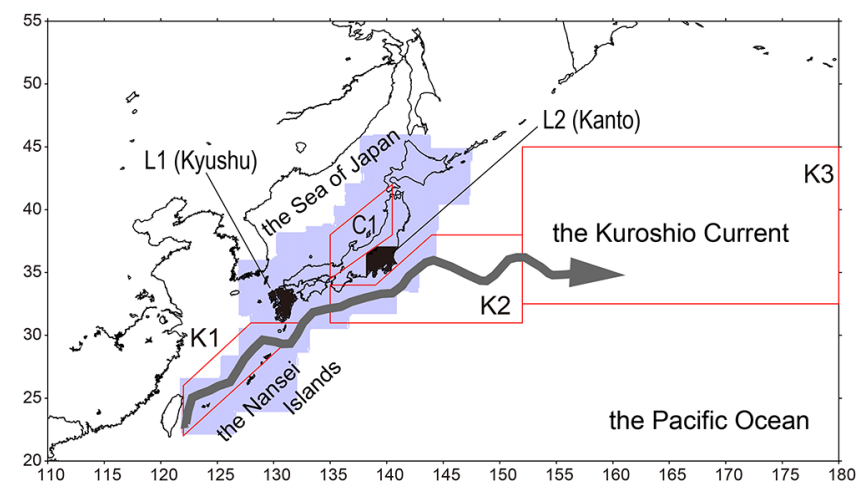

Fig. 1. Analysis region. Red polygons (K1, K2, K3, and $\mathrm{C} 1)$ and black land areas (L1/Kyushu district and L2/Kanto district) indicate areas with high density lightning. The gray line and blue area illustrate the axis of the Kuroshio Current (May 14, 2010) and the observation area of the JMA radar network, respectively.

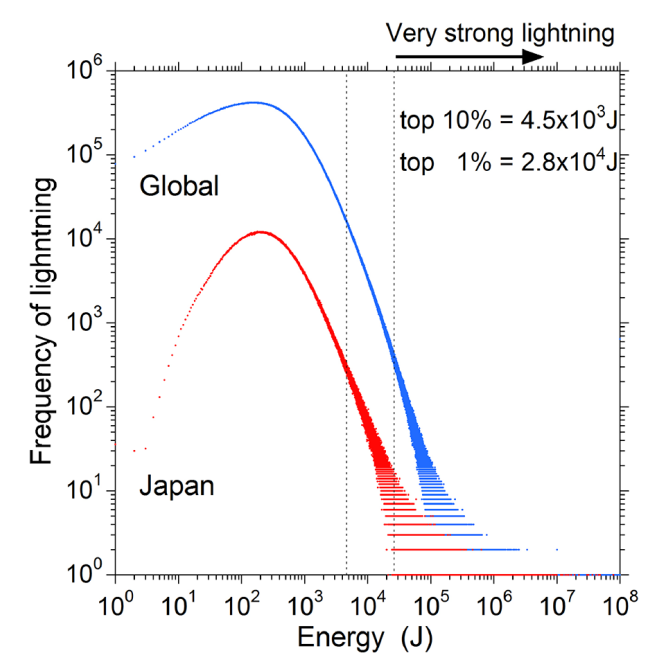

Fig. 2. Frequency distribution of global stroke energy (blue) and over the analysis region (red).

determine the features of lightning over the Japanese archipelago and the surrounding area $\left(20-55^{\circ} \mathrm{N}, 110-180^{\circ} \mathrm{E}\right.$; see Fig. 1). The analysis period is from April 2009 to December 2012. Lightning data were compiled into an hourly gridded data set with resolution of $0.25^{\circ}$ latitude and longitude.

Figure 2 indicates the frequency distribution of stroke energy both globally and within the region of analysis. The dynamic range of stroke energy is very wide, i.e., about $50 \mathrm{~dB}$. The mode value is about $2.5 \times 10^{3} \mathrm{~J}$ and the maximum value exceeds $5 \times 10^{7} \mathrm{~J}$ for both regions.

Because detection efficiency is higher for stronger strokes (Rodger et al. 2004; Abarca et al. 2010) and because the minimum detectable stroke energy of each lightning stroke depends on the minimum observable energy of each WWLLN station (Hutchins et al. 2012b), the reliability of data for weak stroke energy is considered insufficient. Therefore, we focus on lightning with strong stroke energy. The strength of a lightning stroke is classified into 11 categories based on the radiated VLF stroke energy around Japan: 10-quantiles of stroke energy and a category for very strong lightning. For convenience, lightning with radiated VLF stroke energy of more than $4.5 \times 10^{3} \mathrm{~J}$ (top $10 \%=10$ th quantile of stroke energy) and $2.8 \times 10^{4} \mathrm{~J}$ (top 1\%) is defined as strong lightning (S lightning) and very strong lightning (VS lightning), respectively. In this work, attention is focused on VS lightning because it has features that are more obvious than S lightning. Furthermore, we analyze the frequency of lightning and the ratio of VS lightning to all lightning (VS ratio).

\section{Results}

\subsection{Features of the distribution of lightning}

In the analysis period, the number of lightning strokes detected by WWLLN is $1.3 \times 10^{7}$ and their distribution is shown in Fig. $3 a$. Except for the mainland of southern China, the high-density areas occur along the Nansei Islands (K1) and to the south of mainland Japan (K2), corresponding to the Kuroshio Current. Furthermore, it is clear to see that for both V and VS lightning the high-density area extends eastwards (K3) over the Kuroshio extension (Figs. $3 \mathrm{c}, \mathrm{e})$. Regions $\mathrm{K} 1-\mathrm{K} 3$ also correspond to the zone of high rainfall over the ocean (Fig. 3b). In addition, small areas with high density of lightning are found in the Kyushu district (L1) and Kanto district (L2) over land, and the coastal area of the Sea of Japan (C1). It is well known that regions L1 and L2 experience considerable lightning in the warm season and that region $\mathrm{C} 1$ experiences considerable lightning in winter (e.g., JMA 1968). Lightning over region L1 in June to July is associated with the Baiu front, and that over regions L1 and L2 in July to August is due to heat-driven thunderstorms. It is noted that the density of lightning over land areas is lower than that of regions $\mathrm{K} 1$ and $\mathrm{K} 2$.

Figures 3c, e show the distribution of density of $\mathrm{S}$ and VS lightning, respectively. The features of these stronger lightning strokes are quite different from those of other lightning. Most of the stronger lightning occurs over the ocean (Figs. 3c, e) and the ratio of $\mathrm{S}$ and/or VS lightning over the ocean is also larger (Figs. $3 \mathrm{~d}, \mathrm{f})$. It is noted that very high density of stronger lightning is found over the northern Pacific Ocean, even though lightning frequency there is low. The tendency for high density lightning over the ocean is consistent with the results of Hutchins et al. (2013).

By considering the features of each region, we find that the density of lightning exceeds $6.0 \times 10^{-1}$ strokes $/ \mathrm{km}^{2} / \mathrm{yr}$ in region $\mathrm{K} 1$; however, VS lightning hardly ever occurs there. Furthermore, regions L1 and L2 exhibit similar tendencies to region K1. Conversely, region $\mathrm{K} 3$, located over the Kuroshio extension, displays a distinct feature in the VS ratio, i.e., a high VS ratio of over $10 \%$ is found in the north of the zone with high density lightning (Fig. $3 \mathrm{f}$ ). The VS ratio in region $\mathrm{K} 3$ appears large (small) over the area in which lightning scarcely (frequently) occurs. This feature is confirmed for the other regions in the following subsection.

Interestingly, the coastal area of the Sea of Japan (region C1) exhibits a unique feature whereby the density of VS lightning along the coastline exceeds $20 \times 10^{-3}$ strokes $/ \mathrm{km}^{2} / \mathrm{yr}$, which is the highest value in the analysis region (Fig. 3e), even though the density of lightning is less than $5.0 \times 10^{-1}$ strokes $/ \mathrm{km}^{2} / \mathrm{yr}$ (Fig. 3a). Most VS lightning occurs in winter (Fig. 4d) and many researchers have studied these winter thunderstorms from the perspective of positive lightning (e.g., Takeuti and Nakano 1977) and lightning superbolts (e.g., Turman 1977).

\subsection{Seasonal variation of lightning}

Figure 4 presents the seasonal variation in frequency of all lightning and VS lightning, and the VS ratio for each region. The VS ratio for all regions shows a tendency to be large in the cold season and small in the warm season, although consistency in the variation between lightning and VS lightning is not found throughout all the regions. However, four regions (K1, K2, C1, and L1) exhibit at least one month during the warm season in which lightning density is high and the VS ratio is low. It is also interesting that in autumn for region L1 and in spring for region L2 considerable VS lightning occurs without a prominent maximum of lightning. These facts suggest there are two types of atmospheric electrical structure to the cumulonimbus clouds over all the regions, i.e., cumulonimbus clouds with VS lightning and some without. It is well known that there are two types of cumulonimbus clouds that cause winter lightning around the Hokuriku district (region C1) and ordinary summer lightning (Krehbiel et al. 1983; Kitagawa and Michimoto 1994). Kitagawa (1996) highlighted the fact that the duration of the dipole and tripole electrical structures is very short in the developing and mature stages of winter thunderstorms, and suggested that these electrical struc- 


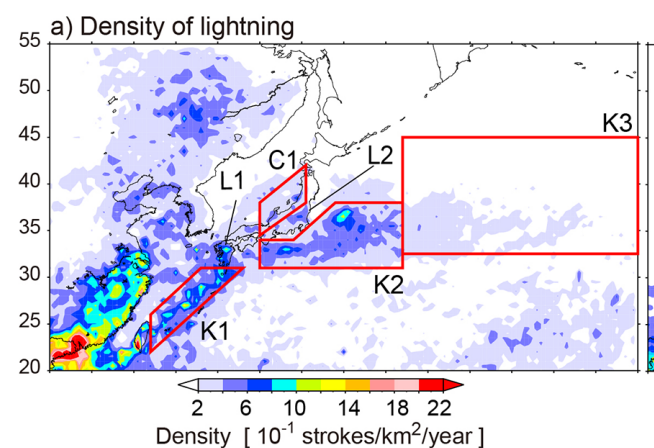

b) GSMaP rainfall amount

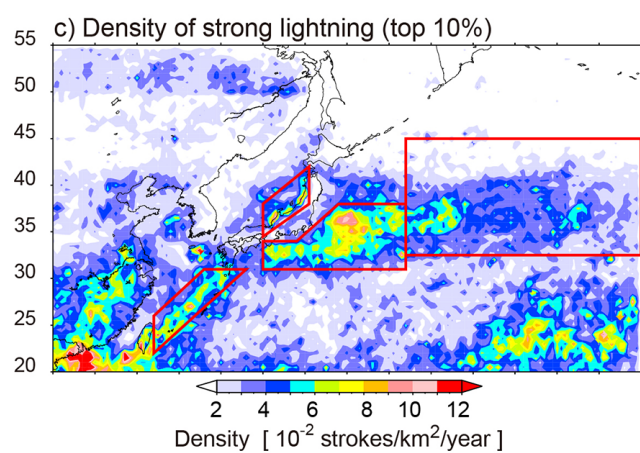

d) Ratio of strong lightning (top $10 \%$ )
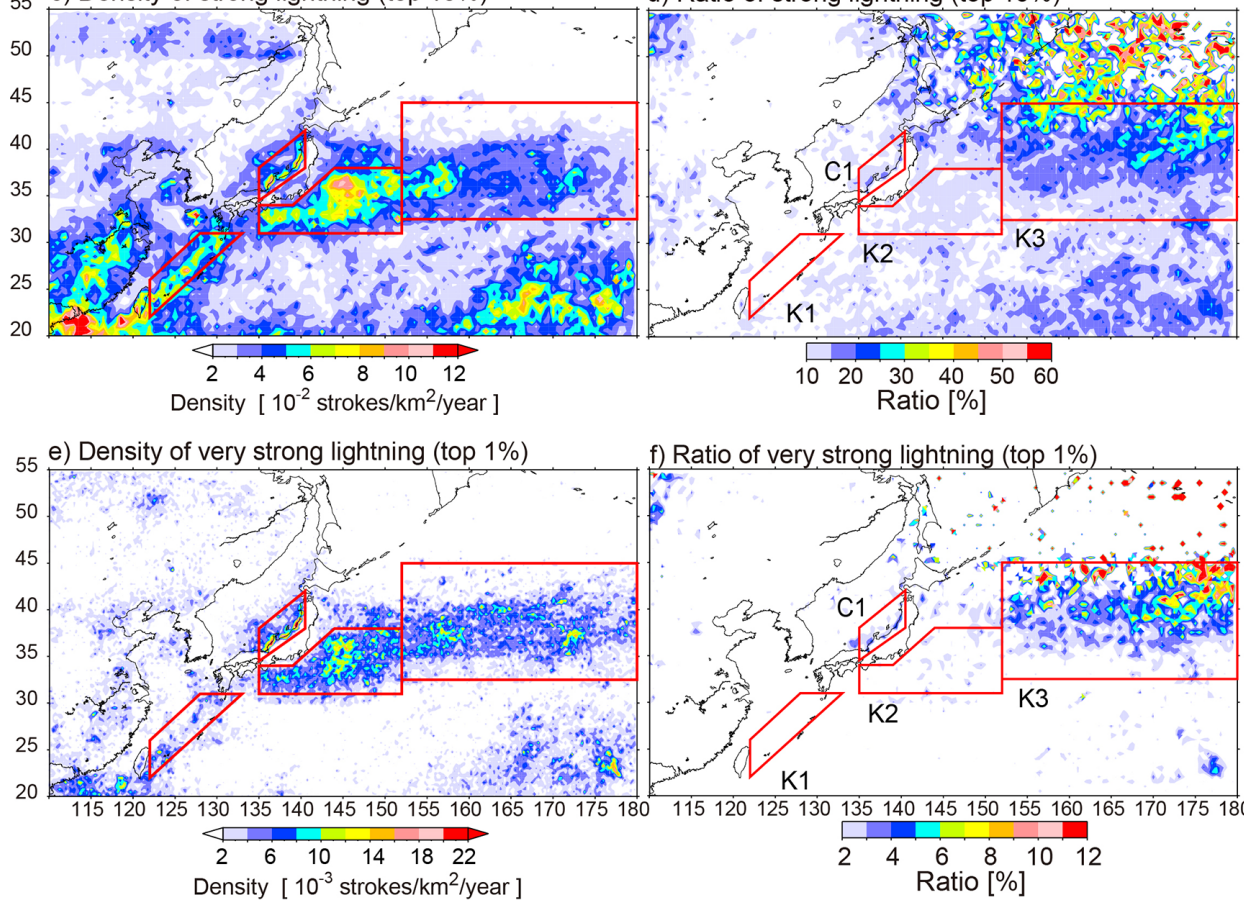

f) Ratio of very strong lightning (top $1 \%$ )

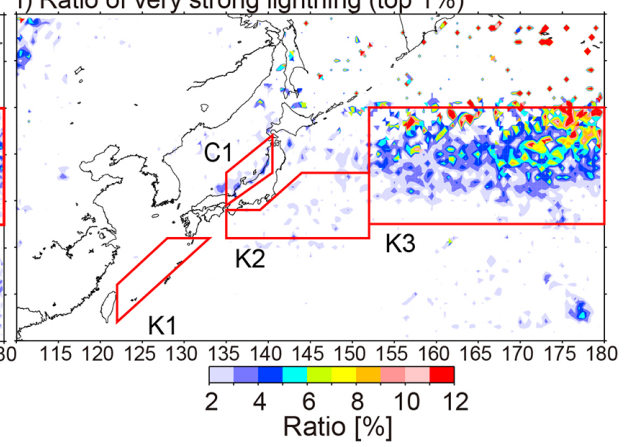

Fig. 3. Distribution of density of lightning detected by WWLLN (a), GSMaP rainfall amount (b), density of S and VS lightning (c and e), and ratio of S and VS lightning ( $\mathrm{d}$ and f). High-density regions $\mathrm{K} 1, \mathrm{~K} 2, \mathrm{~K} 3$, and $\mathrm{C} 1$ are indicated by red polygons. L1 (Kyushu district) and L2 (Kanto district) regions are indicated by arrows in Fig. 3a.
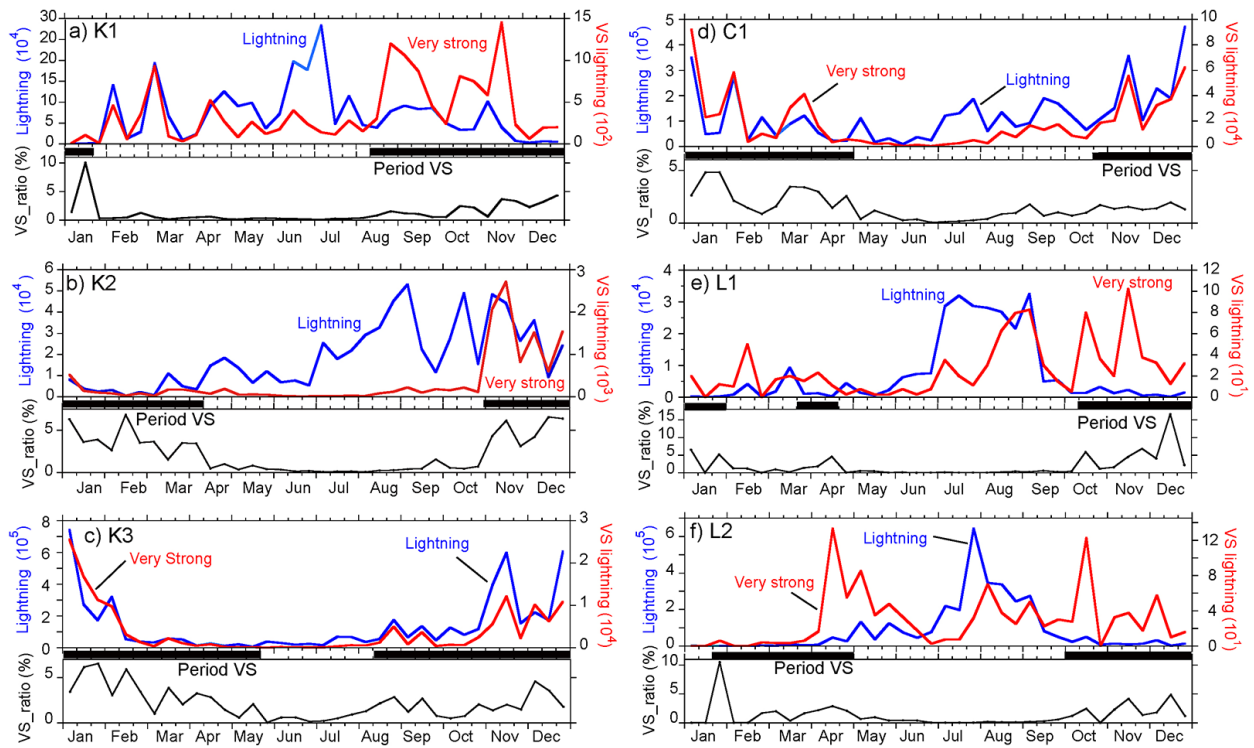

Fig. 4. Seasonal variation of total number of lightning (blue) and VS (red) lightning strokes (upper panel), and VS ratio (lower panel) for each region. Black bar indicates the period in which the VS ratio is relatively large (VS period). 

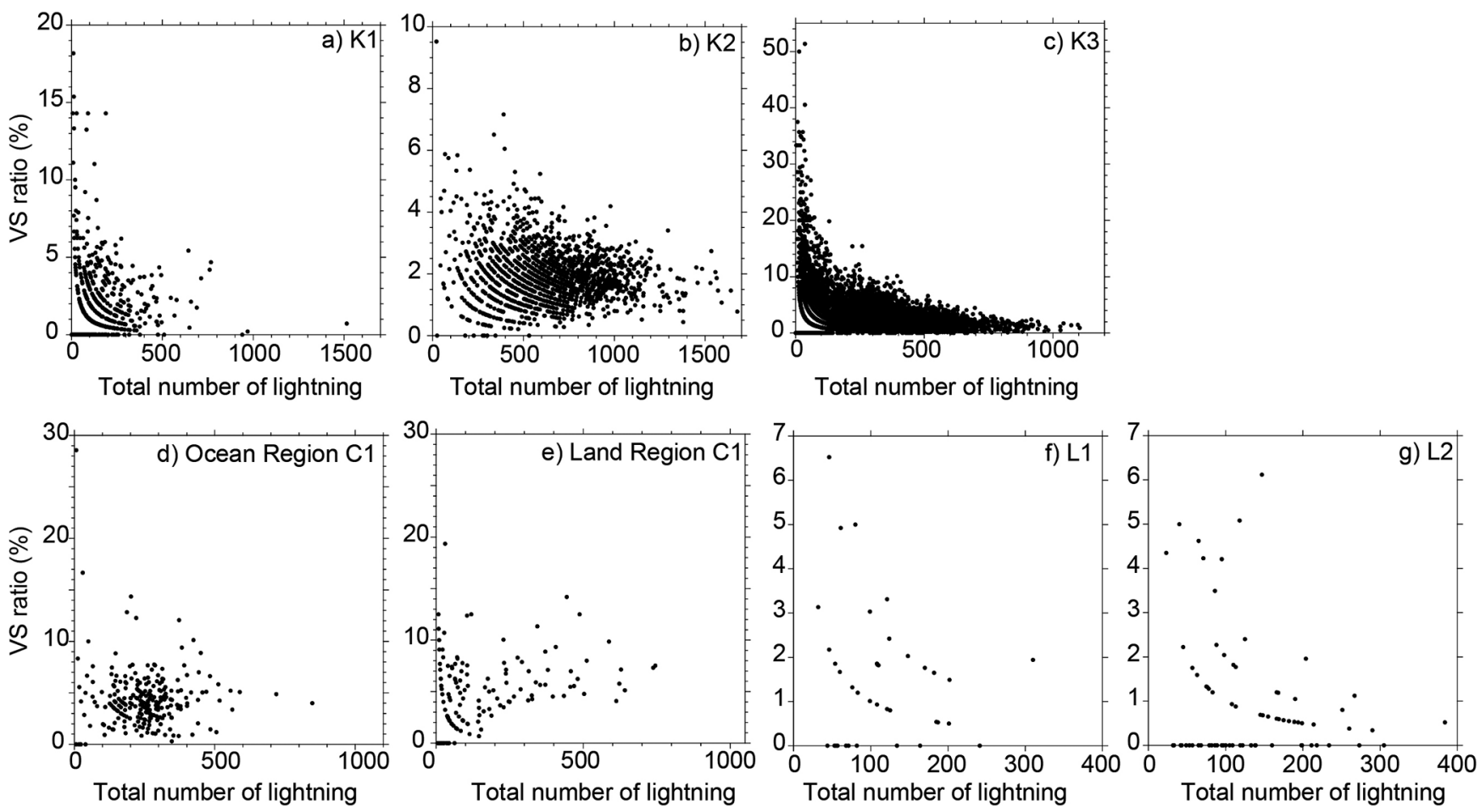

Fig. 5. Relationship between number of lightning strokes and the VS ratio for each region in the VS period. The relationships in region C are presented separately for the ocean (d) and land (e).

tures would be related to a large ratio $(33 \%)$ of positive lightning and unusual amounts of charge exceeding $100 \mathrm{C}$ in the dissipating stage of winter thunderstorms. Investigating whether the two types shown in Fig. 4 are the same as these two types of thunderstorms will be the focus of a future study.

\subsection{Relationship between lightning frequency and VS ratio}

As described in subsection 2.1 , the VS ratio in region $\mathrm{K} 3$ tends to be large in areas where the lightning frequency is small (Figs. 3e, f). This tendency is confirmed for all regions in the period with large VS ratio (VS period), denoted as black bars in Fig. 4. Figure 5 indicates the relationship between the number of lightning strokes and the VS ratio for each grid for all regions. Except for the land in region $\mathrm{C} 1$, it is noted that the VS ratio is large in those grids where the number of lightning strokes is small, i.e., VS lightning occurs frequently in areas with little lightning.

\subsection{Relationship between stroke energy and rain intensity}

Because the development of a cumulonimbus cloud is a minimum requirement for atmospheric electrical activity, it is important to investigate the influence of cumulonimbus cloud development on the strength of stroke energy.

Figures $6 \mathrm{a}, \mathrm{b}, \mathrm{c}$ show the relationship between the strength of the lightning stroke and intensity of radar rain for each region in the VS period, designated in Fig. 4. Intensity of radar rain is defined as the average value of rain intensity over $25 \mathrm{~km}^{2}(5 \times 5$ grids) around the point at which WWLLN lightning was reported. The JMA radar network is unable to observe region $\mathrm{K} 3$ or parts of regions $\mathrm{K} 1$ and $\mathrm{K} 2$, as shown in Fig. 1, but common features for six regions are found. For categories 4 and lower, the rain intensity of category 1 for all regions is the smallest value, and for categories 7 and above, the rain intensity of category 10, except for the land in region $\mathrm{C} 1$, is the smallest value. These common features are also seen in the warm season (not shown).

Similar analysis was performed using the GSMaP products to confirm that these features are common to region K3. Figures $6 \mathrm{~d}$, $\mathrm{e}, \mathrm{f}$ show the relationship between the strength of lightning stroke and intensity of GSMaP rain for each region in the VS period.
The intensity of GSMaP rain is defined as the average value of all GSMaP rain rates in which WWLLN lightning was reported for each grid box. The features obtained from the radar data are similarly recognized in Figs. 6d, e over the oceanic regions K1 and $\mathrm{K} 2$, and the $\mathrm{C} 1$ region, which means that the GSMaP products have sufficient accuracy for this analysis despite the very coarse spatial and temporal resolution. Furthermore, weak and strong lightning also have a tendency to occur in the relatively weak rain area of region K3 (Fig. 6d). In other words, weak and VS lightning tend not to be accompanied by cumulonimbus clouds producing intense rain over the analysis region. However, this tendency should be re-investigated for individual thunderstorms in respect of the evolution of convective and lightning activities.

\section{Summary}

Features of lightning for a four-year period (2009-2012) over the Japanese archipelago and the surrounding area are described using WWLLN data based on global observations of VLF waves. The following results were obtained:

1. The area with high density of lightning extends along the Kuroshio Current. The high-density zone with more than $6.0 \times$ $10^{-1}$ strokes $/ \mathrm{km}^{2} / \mathrm{yr}$ is found to the west of the Nansei Islands; however, very strong lightning (VS lightning) with stroke energy of more than $2.8 \times 10^{4} \mathrm{~J}$ (top $1 \%$ ) scarcely occurs there. Conversely, the density of lightning gradually decreases in the eastern part of the Kuroshio Current, but the frequency of VS lightning increases.

2. The density of lightning over the Japanese archipelago is lower than that over the ocean and VS lightning scarcely occurs over land.

3. Weak and strong lightning tend to occur in areas where rain intensity is not strong. The ratio of VS lightning (VS ratio) is large in those areas with little lightning and it increases in the cold season. 

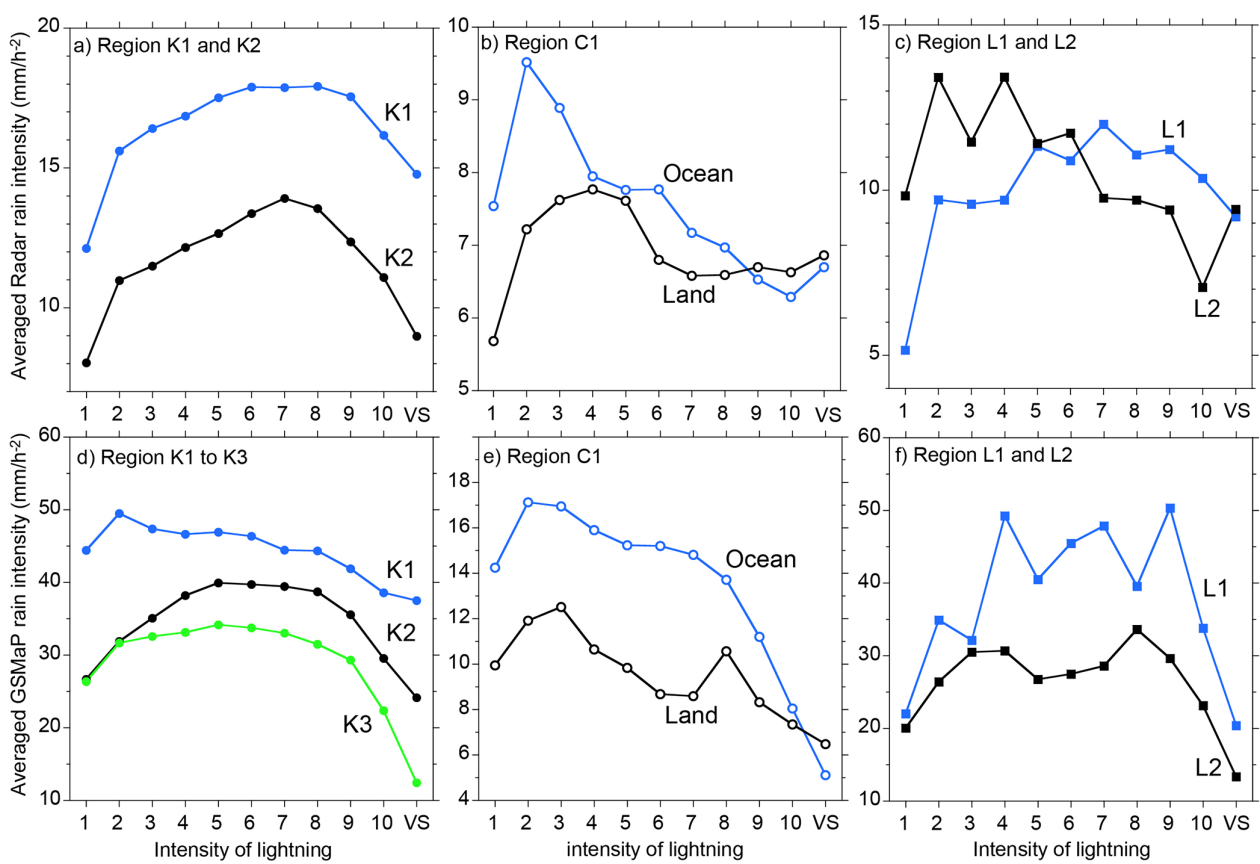

Fig. 6. Relationship between the strength of lightning stroke and intensity of the JMA radar rain $(a-c)$ and GSMaP rain $(d-f)$ for each region in the VS period. Strength of lightning stroke is defined as the 10th quantile of stroke energy and a category for VS lightning is added. Intensity of the JMA radar rain and GSMaP rain is defined as the average value of radar and GSMaP rain when lightning stroke occurred.

\section{Acknowledgments}

Global Satellite Mapping of Precipitation (GSMaP) data were provided by the Japan Aerospace Exploration Agency (JAXA) and Earth Observation Research Center (EORC).

\section{References}

Abarca, S. F., K. L. Corbosiero, and T. J. Galarneau Jr., 2010: An evaluation of the Worldwide Lightning Location Network (WWLLN) using the National Lightning Detection Network (NLDN) as ground truth. J. Geophys. Res., 115, D18206, doi:10.1029/2009JD013411.

Dowden, R. L., J. B. Brundell, and C. J. Rodger, 2002: VLF lightning location by time of group arrival (TOGA) at multiple sites. J. Atmos. Sol. Terr. Phys., 64, 817-830.

Hutchins, M. L., R. H. Holzworth, C. J. Rodger, and J. B. Brundell, 2012a: Far field power of lightning strokes as measured by the World Wide Lightning Location Network. J. Atmos. Oceanic Technol., 29, 1102-1110.

Hutchins, M. L., R. H. Holzworth, J. B. Brundell, and C. J. Rodger, 2012b: Relative detection efficiency of the World Wide Lightning Location Network. Radio Science, doi: 10.1029/2012RS005049.

Hutchins, M. L., R. H. Holzworth, K. S. Virts, J. M. Wallace, and S. Heckman, 2013: Radiated VLF energy differences of land and oceanic lightning. Geophys. Res. Lett., 40, 2390-2394.

Japan Meteorological Agency, 1968: Raiu 10 nenpou, Japan Meteorological Agency (in Japanese).

Kawasaki, Z., and S. Yoshihashi, 1998: TRMM/LIS observations of lightning activity. J. Remote Sensing Society of Japan, 18, 494-501 (in Japanese).

Kitagawa, N., 1989: Long-term variations in thunder-day frequency in Japan. J. Geophys. Res., 94, 13183-13189.

Kitagawa, N., 1996: Meteorological aspects of winter thunderclouds along the Japan Sea coast. Tenki, 43, 89-99 (in Japanese).

Kitagawa, N., and K. Michimoto, 1994: Meteorological and electrical aspects of winter thunderclouds. J. Geophys. Res., 94,
10713-10721.

Krehbiel, P. R., M. Brook, R. L. Lhermitte, and C. L. Lennon, 1983: Lightning charge structure in thunderstorms. Proceedings in Atmospheric Electricity LH Ruhnke, J. Latham, 408410.

Kubota, T., S. Shige, H. Hashizume, K. Aonashi, N. Takahashi, S. Seto, M. Hirose, Y. N. Takayabu, K. Nakagawa, K. Iwanami, T. Ushio, M. Kachi, and K. Okamoto, 2007. Global precipitation map using satelliteborne microwave radiometers by the GSMaP Project: Production and validation. IEEE Trans. Geosci. Remote Sens., 45, 2259-2275.

Rodger, C. J., J. B. Brundell, R. L. Dowden, and N. R. Thomson, 2004: Location accuracy of long distance VLF lightning location network. Ann. Geophys., 22, 747-758.

Saito, M., M. Ishii, F. Fujii, and M. Matsui, 2012: Seasonal variation of frequency of high current lightning discharges observed by JLDN. IEEJ Transactions on Power and Energy, 132, 536-541.

Shindo, T., H. Motoyama, A. Sakai, N. Honma, J. Takami, M. Shimizu, K. Tamura, K. Shinjo, F. Ishikawa, Y. Ueno, M. Ikuta, and D. Takahashi, 2012: Lightning occurrence characteristics in Japan for 17 years: observation results with lightning location systems of electric power utilities from 1992 to 2008. IEEJ Transactions on Electrical and Electronic Engineering, 7, 251-257.

Takeuti, T., and M. Nakano, 1977: On lightning discharges in winter thunderstorm. Electrical Processes in Atmospheres, Darmstdt, Germany, 614-617.

Turman, B. N., 1977: Detection of lightning superbolts. J. Geophys. Res., 82, 2566-2568.

Virts, Katrina S., J. M. Wallace, M. L. Hutchins, and R. H. Holzworth, 2013: Highlights of a new ground-based, hourly global lightning climatology. Bull. Amer. Meteor. Soc., 94, 1381-1391.

Yoshida, H., 2002: Geographical distribution and long-term variations of thunder-day frequency in Japan. Tenki, 49, 279-285 (in Japanese).

Manuscript received 5 February 2014, accepted 10 May 2014 SOLA: https://www.jstage.jst.go.jp/browse/sola/ 